\title{
Un corresponsal del P. Feijoo: Joaquín Saurin Robles
}

A correspondent of Father Feijoo: Joaquín Saurin Robles

María Rosa Saurin de la Iglesia

Università di Urbino

CESXVIII, núm. 28 (2018), págs. 311-342

DOI: https://doi.org/10.17811/cesxviii.28.2018.311-342

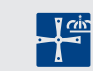




\section{Resumen}

La afable respuesta del P. Feijoo a un joven admirador, en 1750, da pie para esbozar la personalidad del destinatario, aristócrata murciano que había encontrado en el benedictino una guía intelectual. Todo en su evolución sucesiva - ya fuera como Regidor de su ciudad natal o en sus actividades de anticuario, editor de textos raros y en trance de ser olvidados, dramaturgo o miembro de la Sociedad Económica de Amigos del País-, prueba su adhesión a la estrategia sugerida por Feijoo para que España, superando su marginalidad, lograse incorporarse a las Luces ya esparcidas por Europa.

Palabras clave

Feijoo, Ilustración, Saurin, Murcia.

\section{AbSTRACT}

In 1750, the kind answer from P. Feijoo to a young admirer, allows for the sketching out of the recipient's personality, an aristocrat from Murcia, who would have found an intellectual guide in this Benedictine figure. Everything in the development of this personal history whether as councilor of his native city, or in his activities as an antiquarian scholar, editor of rare texts or, in the process of being forgotten, as a playwright or member of Sociedad Económica de Amigos del País, proves his support to the strategy adopted by Feijoo in which Spain, surpassing its marginality, could join the Enlightenment which had already spread throughout Europe.

Key Words

Feijoo, Enlightenment, Saurin, Murcia.

Recibido: 11 de septiembre de 2017. Aceptado: 12 de diciembre de 2017. 
El sosiego del Padre Maestro en su celda de San Vicente de Oviedo estaba destinado a desvanecerse casi al mismo ritmo con que iban triunfando sus escritos. Y por más que pudieran zanjarse de real orden envidias e impugnaciones nada lograría frenar a la muchedumbre de admiradores que lo abrumaban con continuas cartas, empeñados en conseguir respuesta individual. He aquí el insoslayable precio de la fama, croce e delizia a un tiempo, que en la vejez del escritor llegó a convertirse en puro tormento. De ello no hacía misterio, confesando «la fatiga de los correos», el «tedio insuperable» y la impaciencia que le producía la insistencia de tanto admirador impertinente (CE, III, «Dos advertencias a los lectores») $)^{1}$. Quienes lo conocían notaron esa quiebra en la proverbial cortesía epistolar del benedictino y así lo revela este significativo comentario del P. Flórez: «...he oído algunas quexas de quien tubo el buen gusto, y ocasión de escribir al Rmo. Feyjoo, y no ha tenido el gozo que esperaba de ver su letra» (CE, II, «Carta» de Flórez) $)^{2}$. Por eso llama mucho la atención que, en ese estado de ánimo y al filo de sus venerables setenta y cuatro años, respondiese con especial deferencia y prontitud a un lector desconocido y muy joven:

Mi amado Dueño, recivi la de V. S., su fecha de 11 de 9bre, acompañada de el discreto, y hermoso Dialogo, con q. V. S. se dignó favorecerme, y cuya letura me produxo no solo los afectos de complacencia, y gratitud, mas tambien el de admiracion, q. en mi mente se explicó con aquellas palabras de los Montañeses de Judea al ver los prodigiosos principios de el Baptista: Quis putas puer iste erit? [al margen: Lucas cap. $1^{\circ}$ ]. En 16 años tanto? Que será a los 20? Que a los 30?

Aprecio infinito los elogios, q. V. S. tan gratuitamente me dispensa, pero solo uno aceto, como justo, q. es el q. da a mi sinceridad, como asegurado de mi conciencia, de q. nunca he faltado a la oblig.on de practicar esta noble virtud; de modo

\footnotetext{
1 Cito por la primera edición (Benito Jerónimo FEıJoo, Cartas eruditas y curiosas, t. III, Madrid, Imprenta de los Herederos de Francisco del Hierro, 1750, pág. [56]).

2 De nuevo por la primera edición (Enrique FLóREZ, «Carta, que en respuesta a la comisión del Señor Vicario de la Villa...», en Benito Jerónimo Feijoo, Cartas eruditas y curiosas, t. II, Madrid, Imprenta de los Herederos de Francisco del Hierro, 1745, pág. [18]).
} 
q. estoy en animo de protestarlo assi publicamente a la hora de mi muerte. V. S. es acreedor en todo rigor de justicia a q. yo le obedezca en quanto me ordene; como assi mismo lo es a q. ruegue a N. S.r q. conserve y prospere su vida m.s a.s Diz.re 8 de 1750 .

B. L. M. de V. S.

Su mas afecto serv.or i capellan

Fr. Benito Feyjoo

[al margen:] Remito a V. S. ese retrato mio, ya que no puedo lograr la dicha de presentar a sus ojos el original.

S.r D.n Joaquin Saurin y Robles, $\mathrm{am}^{\circ}$, y $\mathrm{Sr}^{3}$.

¿Quién era el afortunado destinatario de una carta que, al parecer, no importuna al escritor? Se trataba de Don Joaquín Saurin Robles, que al dirigirse a Feijoo el 11 de noviembre de 1750 acababa de cumplir dieciséis años pues había nacido el 4 de octubre de 1734 en Murcia, en el seno de una familia de antiguo abolengo asentada en aquel Reino desde su reconquista y distinguida con tierras y honores por Alfonso el Sabio ${ }^{4}$. Admirador temprano de Feijoo, lee y comenta el Teatro crítico y las Cartas eruditas con un íntimo amigo, se entusiasma con estas publicaciones y no duda en tomar partido por el nuevo espíritu que emana de ellas. Estaba casado desde marzo de 1749 con su prima hermana Beatriz Ruiz Dávalos y Saurin, chocante precocidad hoy pero nada insólita en tiempos de ritmo biológico acelerado como aquéllos en que vivía, en que era acuciante «tomar estado». Porque si el mismo Feijoo había recibido la cogulla benedictina a los catorce años, deber de mayorazgo era asegurar cuanto antes

3 Archivo Municipal de Murcia, Colección Alegría, leg. 617, n. ${ }^{\circ} 1$ (en adelante AMM, CA). Dio a conocer esta carta José Pío Tejera y Díaz de Moncada, Biblioteca del Murciano o Ensayo de un Diccionario biográfico y bibliográfico de la Literatura en Murcia, Madrid, Tipografía de la Revista de Archivos, Bibliotecas y Museos, 1922, vol. I, pág. 781. Y la publicó Juan Torres Fontes, «Notas sobre dos cartas de Feijoo», en Ricardo Escavy Zamora, Eulalia Hernández Sánchez, José Miguel Hernández Terres y M. a Isabel López Martínez (eds.), Amica verba in honorem Prof. Antonio Roldán, Murcia, Universidad de Murcia, 2005, t. II, págs. 995-1000, especialmente pág. 999. Hay varios errores en la transcripción: «me dignó» por «se dignó», «que es el de queda» por «que es el que da», «lectura» por «letura», «esplicó» por «explicó», «exit» por «erit», «Acepto» por «Aprecio», «con todo rigor» por «en todo rigor», «a lo que yo» por «a que yo»; además se omite la preposición de en «de 11 de 9re» así como la referencia evangélica que va al margen. Véase, por último, Noelia García Díaz, El epistolario de Benito Jerónimo Feijoo (en los inicios del ensayo moderno), Universidad de Oviedo, Oviedo, Tesis Doctoral, 2016, págs. 212-213 y 581-582.

4 Francisco Cascales, Discursos históricos de la muy noble y muy leal ciudad de Murcia, Segunda impresión. Añadida e ilustrada con algunas notas críticas, Murcia, F. Benedito, 1775, facsímil a cargo de Juan Torres Fontes, Murcia, Academia Alfonso X el Sabio, 1980, passim; además María Rosa SAurin dE LA IgLESIA, Un linaje murciano. Saurin, La Coruña, Rodi, 2013 (edición no venal destinada a la familia). 
la continuidad de su estirpe. Y en efecto, esa y otras circunstancias quedarían registradas poco más tarde en el Catastro de Ensenada, que anota entre los miembros del estado noble a «Don Joachin Saurin, casado, de edad de 20 años, tiene tres hijas, dos tías, un Clérigo de Menores, dos lacayos y cinco criadas» ${ }^{5}$. Tras enviudar en 1756, Saurin contrae nuevo matrimonio en 1760 con Francisca Molina y Borja que le da otras dos hijas y, al fin, el ansiado varón. Enlaces prestigiosos para las hijas afianzaron la trayectoria ascendente del linaje, ininterrumpida desde la Edad Media: María Joaquina, la primogénita, casó con el primer marqués de Melgarejo; la segunda, María de la Concepción, con Nicolás de Avellaneda y Fontes, de antigua familia murciana de regidores; la cuarta, María Francisca Saurin Molina, con José Diego de Alburquerque, miembro de un poderoso linaje lorquino. Y ya muerto su padre, María Josefa, la menor, casó con el primo Alejo Molina y Vera, futuro vizconde de Huerta. Esa cuidadosa estrategia matrimonial reservaría de seguro para el único hijo varón alguna heredera de alcurnia y rango correspondiente pero, si tal hubo, no llegó a cuajar pues Joaquín Saurin Molina (1770-1821), soltero al morir su padre, jamás mudó de estado. Tuvo sin embargo un hijo natural con una mujer del estado llano al que dio su nombre y apellido, estudios jurídicos y acceso a una parte conspicua de su herencia. Se interrumpía así la larga etapa de preeminencia de aquel linaje, entre profundos trastornos políticos, sociales y económicos que dieron fin al Antiguo Régimen mientras se desvanecía la condición jurídica noble en la confusión de los estamentos.

Ese escueto perfil de súbdito prolífico, cuantioso contribuyente y miembro de la poderosa oligarquía municipal de su ciudad cobra mayor vida y relieve gracias a los papeles de su archivo personal que sobrevivieron hasta hoy, aunque muy mutilados, y se conservan en el Municipal de Murcia. De ellos se desprenden datos biográficos interesantes que se enriquecen al cotejarlos con los documentos del Concejo. Un ejemplo: su persona disfrutaba de relevancia pública ya desde el 23 de junio de 1750, fecha en que fue nombrado Alférez Mayor de la ciudad como miembro del estamento nobiliario que la gobernaba; cargo de especial prestigio - y no puramente honorífico, pues iba acompañado de una adecuada retribución-, que requería no solo elevada alcurnia sino también juventud y prestancia física para portar el pendón del cabildo municipal en las solemnidades oficiales. Con este acto iniciaba una presencia en los órganos

5 Murcia 1756 según las Respuestas Generales del Catastro de Ensenada, Madrid, Tabapress, 1993, pág. 101. La publicación de los datos del Reino de Murcia en 1756 explica que se le atribuya la edad que tenía en el momento de la encuesta, o sea, los veinte años de 1754. Corrijo a continuación los datos erróneos sobre sus hijos que ofrece Torres Fontes, «Notas», pág. 996; véase también Saurin dE LA Iglesia, Un linaje, págs. 47-64. 
de gobierno municipales que le correspondía por privilegio hereditario y sería constante en los años sucesivos. Otros documentos señalan gustos y preferencias condicionadas sin duda por la educación esmerada que había recibido en un colegio de la Compañía de Jesús de su tierra ${ }^{6}$. Sus maestros difundieron el buen nombre que había merecido entre ellos, como afirmaba el Padre Burriel años más tarde al recordar que el Padre Quintanilla y otros jesuitas se hacían lenguas de sus «talentos, juicio y aplicación» ${ }^{7}$.

Madurado en la lectura de los clásicos latinos y castellanos, se abre muy pronto a los placeres del espíritu, como enseguida se verá. Y el encuentro con Feijoo acontece precisamente en el momento crítico de formación de la personalidad, cuando la urgencia de ensanchar horizontes y conocimientos corre parejas con la búsqueda de una guía prestigiosa. Feijoo estaba predestinado a serlo. El modo diferente y cautivador que proponía el benedictino de entender el conocimiento, no menos insólito que el modo de adquirirlo y transmitirlo, accesible a todos, tan alejado del clamor de la disputatio y del magister dixit de las aulas, explica el entusiasmo suscitado por aquella pedagogía que es pura indagación en libertad, y que aborda los fundamentos de lo cotidiano bajo una luz nueva, esto es, la simple exigencia de la razón. Hoy nos resulta natural que todo eso suscitara un entusiasmo inseparable de la acogida multitudinaria dispensada a sus libros, por más que en su tiempo no dejara de despertar reservas. Lo cierto es que mientras no es fácil descubrir rastros de la actitud de los alumnos de su largo magisterio ovetense — teólogos y predicadores depositarios de un saber tan inmóvil como el dogma e impartido para más en el convencional latín de las aulas-, subsisten en cambio las vivencias de aquellos otros discípulos espontáneos que le llovieron por obra y gracia de la lectura de sus obras, lejanos fisicamente del maestro, cuya viva voz, sin embargo, venía a suplir con cálida fluidez el español cotidiano de su escritura. A esa legión innumerable de discípulos de elección — vindeiros, les hubiera llamado él en su gallego nativo (y Filgueira Valverde docet) — pertenece Saurin, que se retrata a sí mismo como lector impenitente, acostumbrado a saborear esa afición en el «retiro de [su] librería» y muy al día en cuestiones literarias. El topos del estudioso enfrascado en sus lecturas, inseparable de todo erudito, apunta a una vocación intelectual decidida ya en edad temprana y que hubo de ser alentada por un ambiente fa-

6 «Recibió desde niño, y conforme a su clase, una educación esmerada, y cursó después los estudios de Humanidades y Filosofía en uno de los Colegios de la Compañía de Jesús de su patria, según se desprende de ciertas conclusiones suyas manuscritas que tenemos a la vista [...]. Su principal instrucción, sin embargo, hubo de adquirirla por medio de una constante lectura de los muchos y muy escogidos libros de su abundante biblioteca»: TeJera, Biblioteca, pág. 781.

7 Burriel a Saurin, Toledo, 22-XII-1758, en AMM, CA, leg. 606; véase Apéndice n. ${ }^{\circ} 5$. 
miliar favorable. Y quizá no esté de más — salvando las distancias— recordar el caso de Menéndez Pelayo, poseedor a sus dieciséis años de una biblioteca con sede propia y apoyado en esas aficiones por el padre. Pues bien, lo que el 4 de septiembre de 1750 leía en la suya el murciano comentándolo con un íntimo amigo no era sino el tercer tomo recién publicado de las Cartas eruditas y en particular el episodio mencionado por Feijoo en su dedicatoria a Fernando VI agradeciéndole la protección y salvaguardia contra sus detractores, premio solo igualado en la Historia por el de Hieron, rey de Sicilia, que obligó a sus vasallos a creer cuanto Arquímedes dijese ${ }^{8}$. En torno a este asunto Fabio —alter ego de Saurin en el texto enviado a Feijoo- entabla una conversación con su contertulio Sofronio, tan escéptico como deseoso de averiguar cuánto había de auténtico en la historia del filósofo premiado por su rey. Fabio-Saurin la expone siguiendo a varios testimonios de la Antigüedad y confrontándolos con la interpretación que dieron los modernos. El resultado es un ensayito de veintiocho páginas titulado clásicamente Diálogo $1 .^{\circ}$, en el que la voz cantante de Fabio desentraña el paralelismo con el caso de Feijoo desplegando de manera impecable los resortes académicos de exposición y una erudición minuciosa apuntalada por citas latinas muy bien traídas 9 . El todo rematado con un rotundo «Dixi: Dn. Juachin Saurin».

Discernir y razonar: la actitud docente de Fabio fundada en auctoritates irrefragables y refrendadas con la fuerza de la razón logra, en suma, desvanecer las objeciones de Sofronio que, si al principio afirmaba no tener tragaderas para fábulas e historietas, acaba por no poder resistirse ante la veracidad aplastante de los textos aducidos por su anfitrión. Por lo que concluía satisfecho: «Satis, satis, amigo, que ya no me queda la menor duda». Todo en la factura y estilo del Diálogo remite al admirado modelo feijoniano, como fruto innegable de esa especie de enamoramiento intelectual que hace del maestro un ídolo y de su enseñanza un dechado. Y era ese el homenaje de estima y admiración al que se refería el Padre Maestro en su respuesta. ¿Cómo no había de caerle en gracia el mozo murciano?

Consta además que este, en lo más álgido de la polémica culminada con el «real agrado» de Fernando VI —esto es, entre 1748 en que Soto Marne publica su impugnación y julio de 1750, fecha de la Real Orden de Su Majestad—, andaba rumiando cómo apoyar la causa del benedictino. A ese momento parece referirse el deshilvanado borrador de una carta sin fecha ni destinatario que, con apretada y confusa escritura, ilumina el estado de ánimo del joven y su decisión

8 Cartas eruditas, III, págs. V-VI.

9 Se conserva el borrador en AMM, CA, leg. 617, Caja 30: hay en los dos folios finales alguna variante, o más bien inclusión de párrafos faltosos. 
de acercarse al monje famoso con una defensa a ultranza. Se encaraba allí con «la avilantez y osadía» de los impugnadores del «gran Feijoo» y en particular del P. Soto. Impulsado por un desagrado lindante con la desazón física, muy llamativo por ser él «naturalmente pacífico y de buena pasta» y como tal apreciado de sus contemporáneos — tanto que en su edad adulta seguían reconociéndolo como «el más dulce y pacífico entre los literatos, a quien debimos el comercio más amable, más risueño, más científico...» ${ }^{10}$ —, «muchas veces discurría y ablaba con el $\mathrm{Rm}^{\circ}$ Feijoo le dezia tomaría alguna satisfacion de aquella turbamulta». Hasta que al fin, «como español y amante del crédito de mi Nación», arremete contra los detractores y sus papelones ${ }^{11}$. No se sabe en qué acabaría por traducirse tanta vehemencia mientras pervive, en cambio, la expresión ya embridada de esa indignación que, convertida en homenaje literario a Feijoo y bautizada como Dialogo $1 .^{\circ}$, llegó a Oviedo junto con la carta siguiente:

\section{Carta al Illm Feyjoo}

\section{Illmº. Señor}

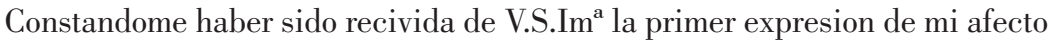
hacia el recurrente merito de su persona con aquella benignidad y dulzura tan propia de su indole noble: toma alientos mi osadia para poner en manos de V.S.I ${ }^{a}$. esta pequeña obrilla, que en defensa de la verdad escribí para satisfacer a un sujeto de esta Ciudad, que qualificaba la especie de Archimedes de Siracusa, que hay en la dedicatoria del tercer tomo de eruditas, de fabulosa.

Suplico a V.S. no atienda a lo que ella es en si, sino es a la voluntad con que la escribo, considerando que el no tener yo mas que diez y seis años puede servir de disculpa a sus muchos yerros.

Pero $\mathrm{S}^{\mathrm{r}}$ r. gue. la importante vida de V.S. m.s a.s para explendor de la Literatura, honor de España y gloria del Mundo.

Murcia y Noviembre 11 de 1750.

Illm ${ }^{\circ}$. Sr.

B.L.M. de V.S. su mas afecto serv.r

Dn. Joachin Saurin

Illm $^{\circ}$. Sr. D. Fr. Benito Feyjóo ${ }^{12}$.

\footnotetext{
10 Juan Lozano, Bastitania y Contestania del Reyno de Murcia con los vestigios de sus ciudades subterráneas, Murcia, Manuel Muñiz, 1794, II, pág. 155.

11 Borrador sin fecha encabezado con un «Muy Señores míos» que se conserva junto con la carta de Feijoo en AMM, CA, leg. 617.

12 AMM, CA, leg. 472, n. 20.
} 
Dos meses, pues, transcurrieron desde el 4 de septiembre de 1750, fecha que va al pie del Diálogo $1 .^{\circ}$, hasta el 11 de noviembre, en que Saurin escribió a Feijoo. Pero entre ambas llama la atención la existencia de un Diálogo $2 .^{\circ}$ rematado el 3 de octubre de aquel mismo año y protagonizado por los mismos interlocutores. También este transcribe una conversación trabada entre los mismos personajes del anterior en la biblioteca de Fabio, a la que Sofronio solía acudir de tertulia al anochecer para comentar y desarrollar las últimas novedades literarias: «Leamos, si a Vd. le pareciere» — dice Sofronio—, «alguna cosa útil y amena». Y la elección recae sobre la que su llegada acababa de interrumpir, que no era sino el paralelo entre Luis XIV y Pedro I, esto es, la número diecinueve del tercer tomo de las Cartas eruditas. La versión escrita de ese entretenimiento o conversación consta de doce páginas, y esa menor extensión, la ausencia de aparato crítico y de notas al margen que daban empaque académico al Díálogo $1 .^{\circ}$, le da al $2 .^{\circ}$ cierto aspecto de tentativa o experimento que anticipa la decisión de comunicarse con quien Saurin consideraba ya como su guía intelectual. Así parece indicarlo la esperanza a la que alude en su carta de «haber sido recivida de V.S.Ima la primer expresión de mi afecto». ¿Qué expresión sería esa? ¿Hubo acaso un intermediario oficioso antes de que el joven se atreviera a escribirle al Padre? Sin que quede claro cómo ni cuándo ocurrió tal acercamiento preliminar, seguramente la madurez intelectual de tales primicias hubo de llamar la atención del benedictino quien, complacido por el «discreto y hermoso Dialogo» que le llegaba desde Murcia no sabría resistirse ante la ingenua espontaneidad de un lector capaz de fagocitar inspiración, método y factura, de razonar «a lo Feijoo» adhiriéndose en pleno a la teoría de la imitación, prestigiosa y practicada en el Siglo ilustrado como clave inigualable para identificarse con el ídolo ${ }^{13}$.

Pero además el Diálogo 2. ${ }^{\circ}$ añade un rasgo importante al retrato de su autor, capaz de nadar y guardar la ropa en un ejercicio de equilibrio digno del mismo benedictino, esto es, sopesando hábilmente méritos y defectos de ambos monarcas, francés y ruso, para acabar alineándose con la postura de Feijoo y las consecuencias políticas de esa actitud. Lo cual le parecía inconveniente a Sofronio, sabedor de que «en Paris se ha quemado este tomo tercero de Cartas»; a lo que Fabio, sin alarmarse, le recuerda el precedente de Mariana —invocado por el mismo Feijoo-, cuyo De rege et Regis institutione había sufrido igual suerte sin graves consecuencias, y por tanto considera todo ello «fabula fabricada por los emulos del Ill.mo Feijoo [pues...] algo antiguo es en Francia usar con nuestros

13 Joaquín Álvarez Barrientos, «Del pasado al presente. Sobre el cambio del concepto de imitación en el siglo XVIII español», Nueva Revista de Filología Hispánica, XXXVIII, 1 (1990), págs. 219-245. 
mas sabios y veraces escritores de esta iniquidad y es constante que el P. Mariana no perdió ni una pequeña parte de estimazion por aquel hecho; luego lo mismo devemos presumir sucederá en el presente» ${ }^{14}$.

La amplia serie de autores antiguos y modernos citados en el Diálogo $1 .^{o}$ plantea la conveniencia de precisar lo que aquella amada biblioteca en donde Fabio escribe y discute pudo proporcionarle a su propietario. Hay citas latinas breves que podrían haberse hecho de memoria por tratarse de autores como Cicerón y Marcial habituales en los estudios ordinarios. Pero ¿Valerio Máximo? ¿y Claudiano? Otras, por su longitud, requerirían el cotejo con el original impreso. A veces está clarísimo el recurso a libros propios que tiene a mano, como cuando para corroborar lo dicho por Cicerón, Fabio exclama «Degeme Vm. tome aquel libro», refiriéndose a Calepino. El conocimiento de algún otro autor moderno parece filtrado a través del mismo Feijoo, como en el caso de Beyerlinck, Rollin, Catrou o Roville. También es posible que recurriera a la biblioteca de los jesuitas, sus maestros ${ }^{15}$, con los que mantuvo una intensa vinculación tanto en la próspera como en la adversa fortuna, y así lo demuestra la estima manifestada por varios de ellos a través de su correspondencia epistolar y el que si, de un lado, suscribía en 1752 las Constituciones de la Congregación del Sagrado Corazón, de otro sería el encargado oficial de justipreciar los bienes de la Compañía tras la expulsión, no sin algunos escrúpulos ${ }^{16}$. Pero, en fin de cuentas, nada se sabe acerca de lo que atesoraba en aquel refugio de meditación y debate amistoso porque su contenido se dispersó, junto con el resto del patrimonio familiar, entre los siglos XIX y XX. Y tampoco aporta luz alguna al respecto el inventario post mortem de los bienes de su propietario fechado en $1790^{17}$. Lo que consta es que los contemporáneos se hacían lenguas de los «muchos y muy escogidos libros» que la formaban, predominantemente de tema histórico y letras humanas junto a textos jurídicos «de que por sí mismo se servía» su dueño ${ }^{18}$. Lo afirmaba alguien que lo conoció personalmente y era además buen

14 Sobre las implicaciones políticas de la actitud de Feijoo, José Luis GómEz URDÁñEz, «Feijoo, político», en Inmaculada Urzainqui y Rodrigo Olay Valdés (eds.), Con la razón y la experiencia. Feijoo 250 años después, Oviedo, Instituto Feijoo de Estudios del Siglo XVIII / Ayuntamiento de Oviedo / Universidad de Oviedo / Ediciones Trea, 2016, págs. 150-182, especialmente págs. 171-177. Y Cristina GonzÁLEz CAizÁN, «La Rusia de Pedro I y la Francia de Luis XIV en el pensamiento político español de mediados del siglo XVIII», Cuadernos de Estudios del Siglo XVIII, 16 (2006), págs. 113-130.

15 María Victoria Játiva Miralles, La biblioteca del Colegio de San Esteban de Murcia, Universidad de Murcia, Murcia, 2007, tesis doctoral en red en https://digitum.um.es/xmlui/handle/10201/109.

16 Informe con su firma sobre justiprecio de las haciendas de los regulares expulsos, 15-II-1770, en AMM, AC, leg. 472, n. ${ }^{\circ} 16$.

17 Inbentario, cuenta y particion de los bienes [...] de Don Joaquin Saurin y Robles, 1790, en AMM, CA, leg. 30, Carpeta 541.

18 Lozano, Bastitania, pág. 158. 
entendedor y poseedor de tesoros literarios, esto es, el canónigo Lozano, cuyas lecturas francesas lo abocaron en tres ocasiones a ciertos contratiempos con la Inquisición ${ }^{19}$. La fama de que gozaba la biblioteca de Saurin explica que no hubiera consulta bibliográfica en Murcia que no contase con su opinión, buena señal de competencia. Se sabe también de la intensa actividad de copia allí realizada para facilitar investigaciones de otros doctos que requerían su colaboración. Valga como ejemplo el del P. Andrés Burriel en 1758 cuando, entregado a su amplio proyecto de coleccionar leyes y fueros, solicitaba la ayuda de Saurin ${ }^{20}$. Por esa razón a sus propios libros hubo de añadirse en ocasiones la presencia en ella de preciosos manuscritos, como el códice del Repartimiento del Reino de Murcia por Alfonso el Sabio temporalmente depositado en ella ${ }^{21}$. Allí se encontraba también la edición original de los Discursos históricos de la Ciudad de Murcia y su Reyno, del Licenciado Cascales, publicada en 1621, que se encargó de reeditar en 1775.

$\mathrm{Y}$, sin lugar a dudas, en aquel aposento ocuparía un lugar preferente el retrato enviado por Feijoo, por más que en la lista genérica de pinturas, «paisitos» y tallas que adornaban la casa y oratorio no se lo mencione de manera alguna ${ }^{22}$. Es probable que se tratase del grabado realizado en 1733 por Palomino sobre un óleo de Bustamante representando al escritor a sus cincuenta y siete años, el primero de una serie destinada a fijar la imagen oficial del benedictino ${ }^{23}$.

Que la lección de Feijoo fue para Saurin mucho más que un mero deslumbramiento juvenil lo prueba su evolución sucesiva, que remite al influjo práctico de aquel modelo sin defraudar el esperanzador pronóstico del Maestro. Las novedosas reflexiones del Teatro y de las Cartas suscitaron su personal modo de intervenir en la sociedad que lo rodeaba y ampliaron su campo de interés. En primer lugar, de la admiración por los escritores clásicos al rastreo de los restos materiales de aquella civilización y otras de la Hispania el paso fue breve y en los papeles de su archivo se puede documentar cómo se acercó a la arqueología, moderna ciencia cuyas bases iban forjándose en España y

19 Antonio Viñao Frago, «El Colegio-Seminario de San Fulgencio. Ilustración, Liberalismo e Inquisición», Áreas, 6 (1986), págs. 18-49, especialmente pág. 25.

20 Burriel a Saurin, Toledo, 22-XII-1758.

21 El libro quedaba en poder de los regidores de la ciudad durante el periodo oficial de su cargo: véanse las vicisitudes de ese manuscrito en Juan Torres FonTes (ed.), Libro del Repartimiento de las tierras hecho a los pobladores de Murcia, Murcia, Real Academia de Alfonso X el Sabio, 1991, vol. 2, «Introducción», pág. X.

22 Inbentario, cuenta y particion de los bienes [...] de Don Joaquin Saurin y Robles, 1790, en AMM, CA, leg. 30, Carpeta 541.

23 Javier González Santos, «Iconografía dieciochista del Padre Feijoo», en Inmaculada Urzainqui (ed.), Feijoo, hoy, Oviedo / Madrid, Instituto Feijoo de Estudios del Siglo XVIII / Fundación Gregorio Marañón, 2003, págs. 160-224. 
el resto de Europa. Etapa decisiva fue precisamente el estudio de las antigüedades históricas de su tierra, en armonía con la tendencia inaugurada por los Borbones y manifestada a partir de 1715 con la creación de instituciones ad hoc y de un corpus básico de testimonios verídicos para forjar una historia crítica de España. En un tiempo que creía en el primado cultural de la Antigüedad y vibraba de emoción ante el descubrimiento de Pompeya y Herculano, la atracción de la nueva disciplina, con sus exigencias de rigor y conocimiento, se afirmó tanto gracias a las instituciones oficialmente creadas para cultivarla como al margen de ellas. Puede observarse cómo, paralelamente y a nivel individual, hubo una interesante labor de anticuarios que estudiando y recogiendo pruebas de la vida milenaria de su región se aprestaban a exhumar reliquias de civilizaciones perdidas: aficiones estas que requerían un gusto educado y conocimientos humanísticos sólidos para que el hallazgo fortuito y aislado se elevase a objeto de estudio y no quedase en simple curiosidad; aficiones que se convierten en actividad científica y se concretan en investigaciones como las que en toda Europa iban consolidando los estudios sobre la Antigüedad. La irradiación de esa moda fue propiciada en España desde la misma familia real, tras el modelo prestigioso de Carlos III, artífice del descubrimiento de Pompeya y Herculano, y de otros hijos de Felipe $\mathrm{V}$ igualmente iniciados en el culto de las antigüedades e interesados en la nueva ciencia, en especial el infante D. Luis, buen conocedor de la numismática.

Murcia se adhirió pronto al espíritu de los primeros reglamentos sobre lo que actualmente se denomina patrimonio cultural, encaminados a proteger monumentos y restos de la Antigüedad. El 29 de junio de 1753 una carta del Marqués de la Ensenada al Corregidor de la ciudad solicitaba enviar a la Casa de Geografía madrileña todas las piezas significativas de la antigüedad local que fueran halladas ${ }^{24}$. A ese estímulo corresponde la entrega del joven Saurin a la investigación histórico-arqueológica sobre el pasado murciano. Siguiendo esa doble línea que los estudios del P. Flórez acreditaban, consta que escribió una Disertación sobre la silla episcopal de San Fulgencio en Cartagena en la que se oponía a la opinión del agustino. Y es lástima que ese escrito haya desaparecido porque hubiera indicado su postura ante tema tan controvertido como la tradición eclesiástica y el culto de los santos locales. Se sabe que lo envió al autor de la España sagrada cuando preparaba el estudio sobre las Medallas de las colonias, municipios y pueblos antiguos de España, y consta también la cortés respuesta de este que, sin pararse en divergencias de opinión, distin-

24 Juan Torres Fontes, Efemérides murcianas (1750-1800), Murcia, Real Academia Alfonso X el Sabio, 1994, pág. 43. 
guió a Saurin eligiéndolo como cicerone en su viaje a Murcia y Cartagena ${ }^{25}$; importante reconocimiento — por venir de quien venía y estaba en el ápice de la fama- de la competencia del joven investigador, buen conocedor del territorio murciano por sus repetidas exploraciones en busca de vestigios de la Antigüedad. En ellas, y según el modelo de los viajes eruditos promovidos por el gobierno pero emprendidas a título individual, sin disponer de patrocinio oficial ni participar en programa alguno gubernativo, Saurin copia inscripciones, recoge monedas, escudriña todo objeto material que pudiese contribuir al conocimiento cabal del pasado local y se convierte en excelente coleccionista de «ídolos, barros, trozos de mosaico, cuadros, monedas, medallas, etc.» ${ }^{26}$. Todo ello recogido como en un verdadero museo de antigüedades en su castillo de Larache, próximo al de Monteagudo, que la opinión general consideraba la primera colección anticuaria de su tiempo ${ }^{27}$. Entre las monedas de aquel gabinete «pasmaron al M. ${ }^{\circ}$ Flórez las de plata batidas en Cartagena, privilegio español desconocido de los anticuarios, sobre batir este metal ${ }^{28}$. Por entonces la fama de su pericia en descifrar e interpretar monedas competía con la del mismísimo Flórez ${ }^{29}$.

En este punto no estará de más traer a cuento tanto la solidez económica como, más aun, las convicciones que respaldaban esa contribución espontánea a la política cultural del gobierno, porque no era solo la cuantiosa fortuna - todavía en el primer cuarto del siglo XIX su único hijo varón figuraba entre los diecisiete titulares de mayor número de vínculos ${ }^{30}$ — sino también la conciencia de superioridad implícita en su privilegiada situación social y un firme sentimiento de la patria lo que inspiraba su aportación al buen nombre de España. Y resulta un tanto sorprendente que no lo entendieran así los herederos al hacer constar otros Hechos que acreditan la munificencia de mi Sr. Abuelo D. Joaquín Saurin Robles, estos ya completamente convencionales ${ }^{31}$.

25 Tejera, Biblioteca, pág. 781. Contradice este extremo Torres Fontes, «Notas», pág. 997: «...no parece que se establecieran muchas afinidades entre ellos, puesto que no lo menciona y sí, en cambio, al canónigo Francisco Gómez de Manzanilla, que le atendió. Flórez no deja de hacer constar su fracaso al no hallar algún fundamento preciso ni "cosa que anteceda al siglo décimo quarto"».

26 Tejera, Biblioteca, pág. 781.

27 José María IbaÑEz, «Tres retratos de murcianos ilustres en la galería de la Real Sociedad Económica, I. D. Antonio Fontes Ortega (1723-1790). II. D. Joaquín Saurin Robles (1732 sic!-1789). III. D. Juan Lozano (1731-1808)», La Verdad, Murcia, n. ${ }^{\circ}$ extraordinario, enero 1924, sin pág.

28 Lozano, Bastitania, pág. 125.

29 Así lo indica una carta fechada en Salamanca en 1761, sin indicación de autor: véase TeJERA, Biblioteca, pág. 782.

30 María Teresa Pérez Picazo, «Mayorazgo y desvinculación en el municipio de Murcia (1750-1850)», Historia, Instituciones, Documentos, 16 (1989), pág. 298.

31 AMM, CA, leg. 472, n. ${ }^{\circ} 30$. 
Esas actividades forman la parte más consistente de su aportación a la arqueología murciana de la que, al parecer, nada se conoce actualmente, según pude deducir de una fugaz conversación que mantuve en noviembre de 2012 en el zaguán del Museo Arqueológico de Murcia con su Director D. Luis Enrique de Miquel Santed. No menos desazonante parece la miopía o ingenuidad cultural de los herederos de la tercera generación: al iniciarse la dispersión de aquellas propiedades José Pío Tejera "pudo admirar parte de aquella colección en el despacho del Excmo. Sr. D. Pedro Pagán, celosísimo compilador y guardador de curiosidades antiguas. Otra parte de la colección, exigua, en casa de Molina Márquez que no ha sabido explicar el motivo de no haberla recibido entera ${ }^{32}$.

Su labor fue individual pero no aislada porque la investigación arqueológica es empeño colectivo, como atestigua la densa red epistolar de amigos y entendedores de que supo rodearse Saurin, aval científico inter pares de una disciplina en formación, con saberes fundados en actitudes críticas y técnicas depuradas. Encuentra pronto el respaldo de la comunidad erudita, de quienes con su talento y conocimientos contribuían a fijar con datos fidedignos los vestigios históricos de España según criterios de razón y veracidad, sin concesiones a lo fabuloso. Ya en 1751 Saurin analiza y coteja las piezas romanas que poseía comunicándose con el P. Nicolás Estrada, de la Compañía de Jesús, al que brindaba «dos monedas de Augusto y un Gordiano» de su gabinete solicitando a su vez la lista de las «que tubiere duplicadas, así de Emperadores, como de Colonias y Municipios de España» ${ }^{33}$. Su dedicación a la numismática, pasión dominante del Siglo ilustrado ${ }^{34}$, se concretaba en una especie de esquema o prontuario titulado Reflexiones sobre las medallas celtibéricas $^{35}$. Y para confirmarla se presentaba el 5 de marzo de 1754 ante la Real Academia Geográfico-Histórica de Valladolid con la Noticia [...] sobre una medalla antigua que discurre pertenecer a Pincia, análisis de una de las «medallas españolas antiguas o desconocidas que se conservan en mi monetario», la de bronce que él atribuye a Pincia de los vacceos, «para que cotejado todo por dicha Real Academia pueda hacer cabal concepto del grado de verosimilitud que merezcan mis reflexiones» y determinar «qué grado de probabilidad tenga

32 Tejera, Biblioteca, pág. 781. El nombre de Pagán — quizá depositario de algunos bienes de Saurin- aparece también en las vicisitudes del códice del repartimiento de Alfonso X a que alude TorRes FonTES, Libro del Repartimiento, pág. 43.

33 Saurin al P. Estrada, Murcia, 2-III-1751, en AMM, CA, leg. 617, n. ${ }^{\circ}$ 3; véase Apéndice n. ${ }^{\circ} 1$.

34 Antonio Mestre SAnchis, «Hacia una gran colección de monedas antiguas en España. El P. Flórez y dos colaboradores desconocidos», Cuadernos de Estudios del Siglo XVIII, 26 (2016), págs. 332-355.

35 Se trata de un par de folios sin fecha en AMM, CA, leg. 472, n. ${ }^{\circ} 4$. 
mi congetura $»^{36}$. Confrontaba así sus planteamientos de principiante con la certidumbre de los peritos sobre una pieza de caracteres identificables con la escritura celtibérica. Y para corroborar su hipótesis recurría a la opinión de Velázquez en su Ensayo sobre los alphabetos de las letras desconocidas que se encuentran en las más antiguas medallas y monumentos de España, publicado por la Real Academia de la Historia en 1752. El interés despertado por la Noticia es patente en el dictamen de los académicos, favorable aunque dubitativo, lo que le permite aquilatar mejor su postura respondiendo puntualmente a los reparos que se le hacían con la Respuesta que Don Joachin Saurin Robles y Serrano Señor de Cox y la Condomina remite al Señor Don Manuel de Junco y Pimentel Señor de las Villas de Carral, Villar y Castrillo de las Piedras y Sri ${ }^{\circ}$ de la Real Academia Histórico-Geographica de Valladolid, en satisfaccion de los eruditos reparos expuestos por este Cab.ro sobre la explicacion de una Medalla antigua, que se discurre pertenecer a Pincia de los Vacceos, cuyo dibujo, con algunas reflexiones acerca de ella se haya remitido a dha. Rl. Academia ${ }^{37}$. La relación con una de las instituciones protagonistas del desarrollo cultural de su tiempo se iniciaba pues con la humildad del neófito porque «mi ánimo ha sido siempre el proponer las dudas que se me ofrecían en este particular para ser enseñado ${ }^{38}$. Talante este, sin embargo, que en nada disminuye una independencia de juicio evidente en apreciaciones como las referidas a Mayans y al Deán Martî ${ }^{39}$.

Varios escritos fechados en esa misma década dan cuenta de sus investigaciones y confirman su estudio de monumentos y monedas antiguas. El que hoy se desconozcan tales hallazgos y actividades parece deberse no solo a haber quedado manuscritos sino también a las particulares costumbres del autor, que «se deshacía facilmente de lo que llamaba sus borrones» ${ }^{40}$. Los que sobrevivieron se conservan en el Archivo Municipal de Murcia ${ }^{41}$ y queda noticia de algún otro gracias a sus corresponsales. Uno de ellos y excelente entendedor, Luis José Velázquez, se hacía eco en 1753 de su intento de salvar los restos del anfiteatro de Cartagena con estas palabras: «No me coge de nuevo lo que V. me avisa acerca de la determinacion que en Cartagena se ha tomado de derribar el Amphitheatro para las obras que allí se intentan hacer. Semejantes providencias

${ }^{36}$ Noticia que remite al Sr. Dn. Nicolás de Montalbo y Abellaneda secretario de la Rl. Academia de Valladolid Dn. Joachin Saurin Robles y Serrano Señor de Cox y la Condomina sobre una medalla antigua, que discurre pertenezer a Pincia, en AMM, CA, leg. 472, n. ${ }^{\circ} 5$.

${ }_{37}$ AMM, CA, leg. 472, n. $^{\circ} 6$, es copia.

38 AMM, CA, leg. 472, n. ${ }^{\circ}$ 7, copia de carta sin destinatario, Murcia 27-XI-1754.

39 Tejera, Biblioteca, pág. 783 y 784.

40 Lozano, Bastitania, pág. 155.

41 AMM, CA, leg. 472, n. ${ }^{\circ}$ 1-30. 
han destruido monumentos tan importantes, como sucedió en el Amphitheatro de Italica que hoy no parece...» ${ }^{42}$. Poco más tarde insistía: «Sobre el monumento de Cartagena escribí a Madrid, para que en caso de ser cierta la especie, tomasen las providencias necesarias». Y remachaba una vez más: «... espero que recogerá cuantas noticias y monumentos puedan descubrirse en esa tierra ${ }^{43}$. También Antonio Valcárcel Pío de Saboya, conde de Lumiares, bien conocido por su estudio de 1773 sobre las Medallas de las colonias, municipios i pueblos antiguos de España hasta hoy no publicadas, le pedía en 1780 «una copia de las Observaciones de V. sobre el theatro de Murviedro, que V. me franqueó, y yo copie pero tubo la desgracia con otros lios de papeles, que se quemaron ${ }^{44}$. De otras exploraciones, en cambio, se desconoce todo, como las que lo condujeron a identificar el municipio romano de Ficaria con la actual Mazarrón, de donde proceden tres estatuas — «Ceres y dos genios o divinidades»- adquiridas en 1868 para el Museo provincial ${ }^{45}$.

Muestra temprana de la labor anticuaria de Saurin son asimismo las Noticias de algunos monumentos antiguos que se hallan existentes en la Ciudad de Murcia y su Jurisdiccion ${ }^{46}$, apuntes sobre los pocos restos antiguos que sobrevivieron en aquella ciudad a «la violencia de los bárbaros» y a las inundaciones periódicas. De ellos enumera tres: la piedra negra con inscripción existente en la portada de San Nicolás, conocida ya por Cascales aunque este no aportase datos históricos acerca de ella; dos piedras, cada una con cabeza cubierta de píleo, en una pared del jardín de la Compañía; y, lo más sobresaliente, el ara de la villa de Espinardo, a las puertas de la ciudad, procedente de Cartagena pero traída a Murcia en tiempo del obispo Don Sancho Dávila y colocada luego por Don Alonso Fajardo en su dominio de Espinardo. Ese destino final en el jardín del marqués del mismo título remite al modelo aristocrático de las hermosas villas romanas, vergel y museo a un tiempo. Ansioso de confirmar el valor de esta aportación suya a la arqueología murciana, Saurin busca una vez más la opinión de los expertos presentando su escrito a la Real Academia GeográficoHistórica de Caballeros de Valladolid para someterlo al dictamen de los sabios.

42 Tejera, Biblioteca, pág. 782.

43 Velázquez a Saurin, Málaga, 23-II-1754: véase Apéndice n. ${ }^{\circ}$ 2; LozAno, págs. 149-150.

44 Lumiares a Saurin, Alicante, 3-I-1780: véase Apéndice n. ${ }^{\circ} 6$. El circo de Murviedro se convirtió en tema polémico por la pretensión de Flórez que, según Mayans, se gloriaba de haberlo descubierto: véase Antonio Mestre, Historia, fueros y actitudes políticas. Mayans y la historiografía del XVIII, Valencia, Publicaciones del Ayuntamiento de Oliva, 1970, pág. 187. Saurin corrigió la opinión del Deán Martí sobre el asunto: véase lo que anotaba Lozano y reproduce TejERA, Biblioteca, pág. 783-784.

45 IвAÑEz, Tres retratos, sin pág.; TeJera, Biblioteca, pág. 782.

46 AMM, CA, leg. 472, n. ${ }^{\circ} 3$; son 14 folios sin fecha, y, por ser copia, sin los dibujos a que se hace referencia en el texto. 
Y de nuevo la atención recibida en esa comunidad de estudiosos, el detallado análisis, los reparos y objeciones de sus miembros, realzan la seriedad de las «eruditas congeturas» del novel arqueólogo, que recibe por ello el espaldarazo para convertirse en académico ${ }^{47}$. Por eso, cuando vuelva a ocuparse poco más tarde del mismo objeto con la Disertación sobre un monumento antiguo en la villa de Espinardo en que se prueba ser ara dedicada a Augusto Cesar, el autor se identificará ya no solo con sus títulos heredados sino también con ese reconocimiento científico debido a su personal esfuerzo: Por Don Joaquin Franc ${ }^{\circ}$ Saurin Robles y Serrano, Señor de la villa de Cox y la Condomina, y Académico actual de la Rl. Academia de Valladolid ${ }^{48}$.

A lo largo de esos años Cincuenta continuará dando a conocer objetos y documentos por él descubiertos y analizados con método y seriedad científica. Y, para aquilatar «el grado de probabilidad de [sus] conjeturas», sometiendo siempre al círculo selecto de los expertos, académicos de reconocida valía, la valoración de sus trabajos. En todos ellos se trasluce aquel pundonor de «español y amante del crédito de mi nación» que había proclamado poco antes como incitación a sostener la dignidad intelectual de la nación. Un matiz apologético, en suma, que no disgustaría a Feijoo. Como tal lo interpretaba uno de sus censores al «dar las gracias [...] igualmente al Sr. D. Joaquin congratulandome de ver que se cultiven en nuestra España las bellas letras con el esmero que ninguno otro siglo con gusto y complacencia de los amantes de la Nación» ${ }^{49}$.

Sin hilar tan fino como Mayans a la hora de juzgar la formación de un epigrafista $^{50}$, se puede considerar el sólido bagaje humanístico de Saurin como base de su aplicación a esa ciencia, en cuyo estudio se adentró intercambiando datos y noticias con otros eruditos cuya falta de especialización era suplida a veces con el dominio de materias afines. Así lo reconocía paladinamente un valedor suyo al presentar a la Real Academia de Valladolid el citado estudio sobre la medalla pinciana: «...yo en la materia confieso mi cortisima, o ninguna inteligencia, pero con la afinidad que tiene con algunas que professo aunque para todas de improporcionados talentos, y por la inclinacion y afecto a esta,

47 Valladolid, 13-XI-1755: Los censores nombrados por esta Real Academia para la Disertación del Sr. Dn. Joaquin Saurin.... Se trataba de Fernando de Velasco, Pedro Velluti y Venegas, Diego de Sierra y Salcedo, que emiten sus reparos: AMM, CA, leg. 472, n. $^{\circ} 2$.

48 La Gazeta de Madrid, 29-XI-1763, pág. 392, daba cuenta de la Junta pública anual de la Real Academia Geographico-Histórica de Valladolid, celebrada el 4 del mismo mes, en que se leyó la Disertación sobre un Monumento antiguo de la Villa de Espinardo, en el Reyno de Murcia, «escrita por D. Joachin Saurino (sic!)».

49 AMM, CA, leg. 472, n. ${ }^{\text {7 }}$ : copia de carta sin firma ni destinatario, que se adivina ser el Secretario de la Academia de Valladolid, Murcia, 29-v-1754.

50 El rigor que exigía para quienes pretendían interpretar inscripciones lo recoge Mestre en Historia, fueros, pág. 220 . 
bastame... $\gg^{51}$. Hubo también aficionados locales y coleccionistas sin nombradía y de formación incierta, como aquel Juan Andrés Estrañ, buen conocedor de medallas e inscripciones ya desaparecido, cuyo monetario acabó siendo fundido por sus herederos ${ }^{52}$. Saurin informaba de su existencia a Velázquez, que respondía así: «Yo aprecio mucho la noticia que V. me da de este escritor español, cuya obra procuraré descubrir y acaso sabrá algo de ella D. Gregorio Mayans por haberse aplicado especialmente a la historia literaria de nuestra nación ${ }^{53}$. Saurin, con toda franqueza, se permitía ponerlo en duda, a juzgar por lo que aduce en carta de ese mismo año a Velázquez ${ }^{54}$. Y seguramente a esos dimes y diretes corresponde una carta de Saurin a Mayans que no tuve ocasión de consultar, así como la respuesta de este desde Oliva en 1753 citada por Lozano ${ }^{55}$.

El acercamiento a Velázquez, limitado al principio a sus escritos, pronto se hizo personal e intenso gracias a otra cuestión que ocupaba entonces al erudito malagueño, el viaje por el Reino de Murcia, parte de aquel gran proyecto que le había encomendado la Real Academia de la Historia, es decir, la formación de una cartografía rigurosa de España destinada a confluir con una historia crítica del país entero ${ }^{56}$. El 9 de agosto de 1755 Velázquez solicitaba de Saurin datos indispensables «para que pueda yo formar un mapa completo de esse reyno, que hasta ahora no hay» ${ }^{57}$. La invitación es recogida y satisfecha con minuciosidad ejemplar en un conjunto de informaciones fiables en grado máximo a las que Saurin había tenido acceso confidencial en su calidad de Regidor de la ciudad ${ }^{58}$.

La correspondencia con Velázquez revela aspectos de Saurin que trascienden las cuestiones arqueológicas y remiten a otros intereses compartidos por ambos, esto es, las bellas letras y la recuperación de clásicos olvidados. Velázquez era ya bien conocido como miembro de aquella Academia del Buen Gusto que la condesa viuda de Lemos albergaba en su salón madrileño y había publicado en 1753 las poesías de Francisco de la Torre (de difícil atribución y que él adjudicó a Quevedo), seguidas en 1754 del tratado sobre el Origen de la poesía castellana, muy estimado en su tiempo. En marzo de 1755 le anunciaba el envío de esa obra a Saurin, cuyo interés por la poética latina y española consta en

51 Copia de la carta al Secretario de la Real Academia de Valladolid, a quien Saurin había enviado su disertación sobre la medalla de Pincia de los vacceos, Murcia, 29-v-1754, en AMM, CA, leg. 472, n. ${ }^{\circ} 7$.

52 Lozano, Bastitania, pág. 153; y Tejera, Biblioteca, pág. 783.

53 Velázquez a Saurin, Málaga, 23-II-1754, en AAM, CA, leg. 472, n. ${ }^{\circ}$ 26; véase Apéndice n. ${ }^{\circ} 2$.

54 Tejera, Biblioteca, pág. 783.

55 Lozano, Bastitania, pág. 148. La reproduce TEJERA, Biblioteca, pág. 782.

56 Luis José Velázquez, Marqués de Valdeflores, Viaje de las Antigüiedades de España (1752-1765), J. Maier Allende (ed.), Madrid, Real Academia de la Historia, 2015, 2 vols.

57 Velázquez a Saurin, Málaga, 9-vIII-1755; véase Apéndice n. ${ }^{\circ} 4$.

58 Saurin a Velázquez, Murcia, 13-III-1755, en AMM, CA, leg. 472, n. . 26; véase Apéndice n. ${ }^{\circ} 3$. 
el recuerdo de sus contemporáneos ${ }^{59}$. Además su acercamiento a la creación literaria en latín y castellano es atestiguado por Lozano, poseedor de «una que otra tragedia» de su amigo así como de «un discurso impreso sobre las letras y oportunidad para ellas en el otro sexo, con la cifra J. S. y quien por ella ganó el premio ${ }^{60}$. La desaparición de esas obras dramáticas solo permite especulaciones sobre estilo, contenido y registro, que bien podría ser el patriótico de la tragedia neoclásica. Del tono menor y festivo practicado en otras ocasiones queda huella en las redondillas a modo de epístola dirigida desde el reposo veraniego de Cartagena al amigo Moral del Moral, chantre de la catedral; y asimismo en el vejamen titulado Llantos de don Francisco Manzanilla Opositor [en unión de un tal señor Arroyo] a la Prebenda Penitenciaria de la Santa Iglesia de Cartagena ${ }^{61}$. Por lo que se refiere al discurso sobre las letras, ya simplemente su título hace vislumbrar una modernidad de planteamientos educativos nada insólita en el contexto español y europeo de aquel tiempo. Por eso, y aun sin poder aducir algo más que conjeturas, quizá no esté de más indicar ciertas inclinaciones y aptitudes de sus hijos Joaquín y María Josefa, de clara impronta paterna: «el gusto de dibuxo en D. Joachin su hixo, como en la Señorita su hermana, el amor de aquel a las letras y pesquisa de libros selectos, no son mas que un derrame del gusto paterno» ${ }^{62}$.

Como otros doctos del Siglo ilustrado, también Saurin se afanó en recoger y publicar textos raros o en trance de desaparecer, por considerarlos la única base atendible para un conocimiento verídico del pasado que favoreciera el resurgir cultural de España. Del mayor interés es la reedición por él patrocinada de un texto fundamental para la historia murciana, estudio detallado de la evolución del Reino desde su reconquista: los Discursos históricos de la Ciudad de Murcia y su Reyno del Licenciado Francisco de Cascales, cuya edición de 1621 poseía. Devolvía con ello a la circulación un texto que por su rareza llevaba trazas de ser olvidado a pesar de ser imprescindible para la historiografía local. Y así, el 4 de diciembre de 1773 Don Francisco Benedicto, del comercio de libros de Murcia, solicitaba licencia para reimprimir los Discursos, precisando: «Esta segunda [edición] la he hecho con la mas escrupulosa exactitud, enteramente literal, y sin que discrepe un ápice de la antigua publicada en Murcia año de

59 Lozano, Bastitania, pág. 158. Confróntese con dos cartas de 1750 celebrando su ingenio y diálogos, en AMM, CA, leg. 472, n. ${ }^{\circ} 24$.

60 Lozano, Bastitania, pág. 155.

61 La primera en AMM, CA, leg. 472, n. ${ }^{\circ}$ 24; véase el vejamen en TEJERA, Biblioteca, pág. 783.

62 Lozano, Bastitania, pág. 155. Actitud explícita en la descripción de los monumentos de Cartagena que hacía Joaquín Saurin Molina, el único hijo varón, para satisfacer la curiosidad de su hermana menor: Joaquín Saurin Molina a Mi amada hermana María Pepa, Santa Lucía de Cartagena, 13-VIII-1803, en AMM, CA, leg. 606. 
1621, de la que me franqueó el libro que sirve de original el Señor Don Joaquin Saurin y Robles, de la Real Academia de Cavalleros de Valladolid, quien como Noble Patricio, y amante de las letras, ha protegido esta empresa» ${ }^{63}$. También a su iniciativa se debió la recuperación de las Décadas del Licenciado Cascales ${ }^{64}$.

Idénticas exigencias de autenticidad y rigor científico sellaron su amistad con Antonio Valcárcel Pío de Saboya, conde de Lumiares — muy influido por el criticismo histórico de Mayans y en relación constante con el erudito valenciano-, entregado a la edición exacta y fiel de fuentes para la Historia ${ }^{65}$. Lumiares, tras intensos estudios en el país valenciano, le anunciaba a Saurin con orgullo su Thesoro de inscripciones del Reino de Valencia, «la colección más completa que abrá por su exactitud» ${ }^{66}$. Y aplicando los mismos criterios de fidelidad al original se proponía encomendar a Sancha la reedición de la Crónica de los Reyes Católicos de Hernando del Pulgar. Sus cartas al murciano revelan la simpática intimidad que los unía — el tuteo, la alusión a la familia de su corresponsal—, esto es, la de dos buenos amigos que comparten datos de trabajos propios y ajenos, colaboran en la interpretación de inscripciones y coinciden también en sus críticas a la superficialidad de otros investigadores.

Al interés intrínseco de este corpus epistolar se añaden además detalles al parecer marginales y, con todo, significativos. Ejemplo curioso es el de Velázquez cuando acompaña el apellido de su corresponsal con la preposición de. ¿Conocía acaso el muy docto malagueño las raíces provenzales de su amigo? Porque si en 1611 Gaspar Escolano registraba entre los caballeros que acompañaron a Murcia al rey Don Jaime a «un Saurin decendiente de Mosiur de Saurin ${ }^{67}$, de entonces acá ningún miembro de la familia se sirvió jamás de semejante particularidad. Por añadidura, indicadores de arraigo nobiliario en el territorio tales como ese de francés o el von und zu germánico carecen de valor en el mundo hispánico donde su uso denota si acaso solo esnobismo ${ }^{68}$. Por otra parte conviene destacar asimismo la costumbre generalizada en la familia —antes y después de cualquier normalización académica- de no marcar con acento gráfico la última sílaba del apellido. Y ya que este pervivió en Francia y Gran

${ }^{63}$ Don Francisco Benedicto del comercio de libros de la Ciudad de Murcia, solicita licencia para reimprimir los Discursos históricos de la Ciudad de Murcia y su Reyno, del Licenciado Cascales, 4-XII-1773, en Archivo Histórico Nacional, Consejos, leg. 5534-55.

${ }^{64}$ Licencia para reimprimir las Décadas de Cascales, 20-VII-1775, en AMM, CA, leg. 472, n. ${ }^{17}$.

65 Mestre, Historia, fueros, págs. 248-256.

66 Lumiares a Saurin, Valencia, 5-v-1786, en AMM, CA, leg. 617, Caja 30; véase Apéndice n. ${ }^{\circ} 7$.

67 Gaspar Escolano, Segunda parte de la Década primera de la Historia de la Insigne y Coronada Ciudad y Reyno de Valencia, Valencia, Por Pedro Patricio Mey, 1611, t. IV, pág. 46.

${ }_{68}$ José Godoy Alcántara, Ensayo histórico etimológico filológico sobre los apellidos castellanos, Madrid, Imprenta y Estereotipia de M. Rivadeneira, 1871, págs. 196-201. 
Bretaña tal como era en origen — es decir, sin tilde- e identifica a algunos personajes de relieve, no parece apropiado someterlo a nuestra normativa actual.

Esta semblanza de Saurin no quedaría completa sin añadir a sus rasgos de hombre de estudio otros que trascienden tanto la labor histórico-arqueológica como los vuelos del espíritu y son, en concreto, los pertenecientes al ámbito institucional. Igual que sus mayores, Saurin tuvo responsabilidades de gobierno en su ciudad y creció moldeado entre los polos de influencia nobiliario y religioso que la presidían. Murcia, ciudad amurallada, con sus puertas que se cerraban al anochecer, sus once parroquias históricas, sus doce conventos de frailes y ocho de monjas y su catedral, sede de la diócesis cartaginense, presentaba a mediados del siglo XVIII una importante concentración de jerarquías eclesiásticas y una fuerte impregnación religiosa de gustos, hábitos mentales y bagaje cultural. Todo ello está bien presente en el horizonte familiar de nuestro hombre, con miembros pertenecientes al alto clero como su tío y homónimo Don Joaquín Saurin Palmir, colegial en Salamanca del Colegio Mayor de Cuenca y canónigo en Ciudad Rodrigo antes de recalar en Murcia con la misma dignidad. Y en la generación anterior el doctoral Don Antonio Saurin, bajo cuyo canonicato fue erigida la preciosa fachada barroca de la catedral. En ese ambiente urbano quedó enmarcada la actuación pública de Saurin y su participación en dos grandes proyectos de la política ilustrada, esto es, la reforma municipal y la Sociedad Económica de Amigos del País de su ciudad natal.

Quedan pruebas de la incorporación de Saurin al Concejo al inaugurarse las reformas de Campomanes, dirigidas a vivificar la institución municipal permitiendo que el hombre común compartiese el gobierno local con la aristocracia. Con ese objeto fueron creados los cargos de Diputado y Síndico Personero del Público que, aun sin lograr efectos llamativos, prometían salvaguardar mejor el interés público ${ }^{69}$. Saurin fue elegido en 1766 Personero del Público, en 1769 Personero suplente y luego en propiedad, siendo reelegido sucesivamente en $1770,1774,1783,1786$ y $1789^{70}$. Su cargo lo convertía en responsable del uso de los caudales públicos, y el modo en que lo desempeñó se conserva en un episodio significativo recogido en sus papeles: en junio de 1766 exponía la urgencia de proteger la ciudad contra las devastadoras riadas del Segura reconstruyendo el murallón del Arenal, el puente de la parroquia de San Juan y otras obras ya presupuestadas que habían de concluirse aquel verano. Nada se hizo en los tres años siguientes y, a pesar de la terrible inundación de octubre

69 Antonio Domínguez Ortiz, Sociedad y Estado en el siglo XVIII español, Barcelona, Ariel, 1976, págs. 454-475.

70 Francisco Javier Guillamón Álvarez, Regidores de la ciudad de Murcia (1750-1836), Murcia, Universidad de Murcia, 1989, passim. 
de 1769, el Concejo, ignorando aquella amenaza, decidía emplear fondos extraordinarios para construir una nueva Casa de Comedias. Se aducían razones de peso: las sustanciosas ganancias producidas por los espectáculos teatrales prometían multiplicarse si se aumentaba el aforo, cosa imposible dadas las exiguas dimensiones del teatro ya existente. El Personero rechaza esa decisión de la mayoría, la cual, sin embargo, consideraba una «desgracia para los caudales públicos» prescindir de los ingresos que produciría un nuevo teatro. Cuando el 30 de enero de 1770 el Concejo aprueba su construcción anteponiéndola a las obras del río, el Personero «en nombre del Público» y ante el riesgo cierto para la ciudad y sus habitantes se niega a autorizar la inversión en obras superfluas de lo presupuestado para otras inaplazables. En vano. La tensión del enfrentamiento se vislumbra en la actitud del Diputado derrotado, que exige testimonio de su protesta y conservándolo entre sus papeles lo convirtió en una página de la autobiografía que jamás llegó a escribir ${ }^{71}$.

El temor de las riadas pasaba así a segundo término para que la boyante Casa de Comedias pudiese seguir engrosando las finanzas municipales. El rumbo del esparcimiento colectivo, gustos y modas, quedaba allí marcado en una sucesión de diversiones que al alimón con gremios y cofradías solemnizaban las festividades sacro-profanas con comedias, ópera italiana, volatines, toros, al lado de procesiones, rogativas y autos sacramentales... ${ }^{72}$. Todas las alegrías de la vivacidad mediterránea acabaron en 1787, cuando la misión de Fr. Diego José de Cádiz, adalid del movimiento ultraconservador, frenó en seco el avance de la política de espectáculos practicada por el Concejo, a su entender peligrosamente secularizadora. El capuchino, famoso beligerante contra cualquier apertura a lo moderno, lograba trastornar el concepto de diversión pública rompiendo el relativo equilibrio entre las dos instancias de poder de la ciudad, y con él todo un universo mental. El éxito multitudinario y el apasionamiento con que siguieron su cruzada los murcianos lo recuerda hasta hoy la lápida colocada entonces en la iglesia de Santo Domingo, en la céntrica plaza del mercado ${ }^{73}$. Como coronación, el misionero junto con los curas de las once parroquias de la ciudad pidió a la autoridad que se prohibieran las comedias. La muerte de Saurin en 1789 lo libró de ver los efectos de la ofensiva ultramontana en Murcia, agravados por la tormenta ya desencadenada en Francia. Y esa coyuntura explica que su amigo el canónigo Lozano pronunciase un sermón en la catedral

71 Licencia para construir un teatro en Murcia, 27-III-1770, en AMM, CA, leg. 472, n. ${ }^{\circ} 15$.

72 Torres Fontes, Efemérides murcianas, passim.

73 Alfonso Rovira y GÁLvez, Relacion de lo ocurrido en la Mision que ha hecho en la Ciudad de Murcia desde el dia 11 de abril de este presente año de 1787 hasta el 22 del mismo el M. R.P. Fr. Diego Josef de Cadiz, Misionero Apostólico y Capuchino de la Provincia de Andalucía, Cádiz, Antonio Murguía, 1787. 
el 18 de marzo de 1790 en el que lamentaba el auge de las representaciones teatrales afirmando que todos los cristianos que concurrieran por propia voluntad a las comedias pecaban mortalmente ${ }^{74}$.

Acontecimientos anteriores y muy positivos llevaron a Saurin a cooperar en aquel plan general de resurgimiento que fueron las Sociedades Económicas de Amigos del País. El 13 de mayo de 1776 Murcia vio cuajar la suya en torno a fuertes personalidades de la ciudad que la animaron con su dinamismo y su fortuna personal, tal como proponía Campomanes al incitar a las minorías selectas a promover la prosperidad de España. Sus dos primeros miembros, Don Antonio Fontes Ortega y Don Joaquín Saurin Robles, del estado noble no titulado, fueron elegidos en la sesión inicial —el 17 de diciembre de 1777 como Director y Censor respectivamente. El ascendiente personal de ambos dio fuerte impulso inicial a la acción conjunta de un puñado de convecinos en aquella singular experiencia de gobierno de «los mejores» por talento, experiencia e iniciativa, independientemente de su nacimiento. Al protagonismo del estamento privilegiado se le señalaban en este proyecto nuevas responsabilidades en la sociedad moderna, según las indicaciones de Campomanes: «La nobleza de las provincias, que por lo común vive ociosa, ocuparía en estas Sociedades económicas, en los experimentos y en el desempeño de las obligaciones de que más adelante se tratará, útilmente su tiempo, y sin desembolso alguno del Estado serían los nobles los proveedores de la industria y el apoyo permanente de sus compatriotas» ${ }^{75}$. Así flanqueado por sus afines de varios niveles —magistrados, eclesiásticos, catedráticos, funcionarios—, el estamento superior aportó su clara visión del objetivo a alcanzar: contrarrestar el atraso de artes y manufacturas, difundir la enseñanza elemental y las ciencias aplicadas, incrementar la beneficencia en un país minado por el malestar de los más pobres. Inspirándose en los estatutos de la Sociedad Económica de Madrid la unión de los adeptos a las Luces de Murcia tomó medidas para atenuar el acuciante problema de los vagos creando escuelas de hilados, luego instaladas en el Real Hospicio de Misericordia, uno de cuyos fundadores fue Saurin ${ }^{76}$. Se establecieron escuelas de enseñanza primaria y profesional para ambos sexos y una de dibujo transformada luego en Academia de Bellas Artes que el Obispo Rubín de Celis dotó

\footnotetext{
74 Juan Barceló JiméNEZ, «El Antiteatro del canónigo Lozano», Murgetana, 30 (1969), págs. 63-69.

75 Pedro Rodríguez de Campomanes, Discurso sobre el fomento de la industria popular, J. Reeder (ed.), Madrid, Instituto de Estudios Fiscales, 1975, pág. 72.

76 IваÑEz, «Tres retratos», sin pág. Además: Informes de las Reales Sociedades Económicas de Madrid y Murcia sobre erección, dotación y gobierno de Hospicios Casas de Misericordia, Madrid, 1781, en Juan SEMPERE y Guarinos, Ensayo de una biblioteca de los mejores escritores del reinado de Carlos III, Madrid, 1789, V, págs. 203-205, ed. facsímil a cargo de Teófanes Egido, Junta de Castilla y León, Valladolid, 1997.
} 
generosamente $^{77}$. Dirigida por Salzillo, Saurin la albergó en un edificio de su propiedad mientras Fontes establecía de su propio peculio premios para los alumnos sobresalientes. También al fundarse las escuelas de hilazas para ambos sexos concurrieron los socios con sus caudales, siguiendo la sugerencia de Campomanes: «Entre las limosnas que los Prelados, el clero y los ricos podrían aplicar a las familias, serían de gran provecho y ventaja los tornos, los telares y la corta enseñanza para la juventud, asalariando a los principios maestros y maestras de tales géneros» ${ }^{78}$. Por añadidura cada uno de los socios contribuía con una aportación o cuota anual de sesenta reales.

No es de este lugar valorar la obra de la Sociedad ni las limitaciones derivadas del inmovilismo de un ambiente dominado por terratenientes bien avenidos con la estructura jurídico-económica existente, y por la insignificancia de una clase emprendedora ${ }^{79}$. Como quiera que sea, los logros de la Sociedad adquieren más relieve si se prescinde del empeño en atisbar precoces actitudes burguesas en las reformas de la Ilustración, que en Murcia iban impregnadas de valores bien distintos. Se diría más bien que el actual y omnipresente tópico de la mentalidad burguesa de los Amigos del País desdibuja el dinamismo y la apertura mental de muchos de sus miembros que, desde otras convicciones y estilo de vida, se entregaron en cuerpo y alma a aquella empresa de modernidad y eficiencia.

Las funciones de Censor que Saurin desempeñó entre 1782 y 1788 lo llevaron a intervenir en todas las decisiones de la Sociedad por ser tarea de ese cargo el informar sobre proyectos de utilidad social y juzgar la de las propuestas. Algún informe lleva su firma, como el plan de escuelas patrióticas de ambos sexos creadas por la Sociedad a sus expensas en 1788; y asimismo el informe sobre el Seminario de Nobles, respuesta a la Real Orden de 3 de marzo de 1786 que interrogaba a las Sociedades Económicas sobre cómo establecer una enseñanza adecuada al estamento privilegiado. Otros son fruto de la colaboración entre socios. Y es probable que en ese contexto de renovación pedagógica surgiera también el antes citado Discurso sobre las letras y oportunidad para ellas en el otro sexo.

Saurin murió el 21 de noviembre de 1789 y fue sepultado en la ermita de Santa Quiteria, habilitada para el servicio parroquial mientras se reedificaba la

77 Noticia de lo actuado por la Real Sociedad Económica de Amigos del País de esta Ciudad de Murcia, en beneficio de la Patria, y del Estado, desde su erección hasta el año de 1800. Formada por acuerdo de la misma Sociedad por uno de sus individuos, Murcia, Juan Vicente Teruel, s. f. ni págs.

78 Campomanes, Discurso sobre el fomento, pág. 53.

79 Francisco J. Flores Arroyuelo, Sociedad murciana e Ilustración, Murcia, Academia Alfonso X el Sabio, 1977, pág. 24 y passim. También Matías Velázquez Martínez, La Sociedad Económica de Amigos del País del Reino de Murcia: la Institución, los hombres y el dinero (1777-1820), Murcia, Consejería de Cultura, Educación y Turismo, 1989. 
iglesia de San Lorenzo de la que era feligrés. La ermita fue demolida durante el primer gobierno liberal ${ }^{80}$ y en su lugar existe hoy un aparcamiento público. También su morada en la calle de San Lorenzo, del Zoco o de Saurin — que de las tres maneras era conocida- dejó paso a anónimos bloques de pisos durante la remodelación urbana de los años Sesenta; pero ya en sus últimos tiempos había servido de cuartelillo a la Guardia Civil. La calle lleva ahora el nombre del pintor Alejandro Seiquer, premiado en Paris en 1878.

Saurin llegó a alcanzar, efectivamente, aquella plenitud intelectual que le pronosticaba Feijoo y, desde el destino ya trazado por su nacimiento, supo aplicarla al desarrollo general que la Ilustración quería para España. Desde el interés inicial por la veritas histórica hasta la dedicación al desarrollo social y económico junto a los Amigos del País, todo en su vida y actuación lo adscribe a aquella minoría que por cultura y apertura mental estaba preparada para colaborar en las innovaciones de Carlos III. Todo en ella remite a la tendencia del pensamiento europeo de su siglo hacia aquel movimiento renovador de ideas y costumbres que llamamos Ilustración, cuyo mensaje de claridad y rigor, tolerancia y razón logró en España máxima expansión partiendo de Feijoo. Millares de lectores anónimos del benedictino adoptaron, cada cual a su manera, la atractiva receta para lograr cambios colectivos que emanaba de sus libros. Y así, por obra y gracia de aquella lectura, al favor de la Corte con el que ya contaba el escritor, se sumó el de muchos miembros del estamento privilegiado dotados de espíritu crítico e influencia social suficiente para abrir espacios de debate público. Saurin fue uno de ellos. Del Rey abajo, los vínculos que así se fueron entretejiendo permitieron la irradiación de las Luces hasta las clases inferiores de la sociedad.

\section{Apéndices}

Joaquín Saurin al P. Nicolás Estrada, Murcia, 2-III-1751.

AMM, CA, leg. 617, n. ${ }^{\circ}$ 3: «Carta que escribi al Rmº P.e Nicolas Estrada de la Compañía de Jesus remitiendole las dos medallas que se espresan la de Gordiano, de segunda forma, y tambien la de Gordiano de la que tube la respuesta adjunta» [falta esta].

80 IвAÑEZ, «Tres retratos», sin pág. 
$\mathrm{Rm}^{\mathrm{o}} \mathrm{P} \cdot \mathrm{Mtr}^{\mathrm{o}}$

Muy Señor mio: haviendome mostrado la lista de las monedas Romanas,

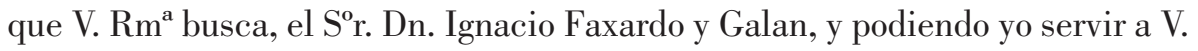
$\mathrm{Rm}^{\mathrm{a}}$ con dos q.e son de Augusto, y un gordiano, lo executo gustoso remitiendolas con dho. $\mathrm{S}^{\mathrm{o}}$. No dudando V. $\mathrm{Rm}^{\mathrm{a}}$ sera para mi de la mayor complacencia el que sean de su agrado.

Supp.c ${ }^{\circ}$ a V.R. me haga el favor de embiarme lista de las monedas q.e tubiere duplicadas, assí de Emperadores, como de Colonias, y Municipios de España, quedando yo en el encargo de practicar quantas diligencias sean posibles a fin de descubrir las q.e a V. Rm ${ }^{\text {a }}$ faltan, y remitirlas con la mayor brebedad.

$\mathrm{Nr}^{\circ} \mathrm{S}^{\mathrm{o}}$ r. g.e a V. $\mathrm{Rm}^{\mathrm{a}}$. m.s a.s

Murc $^{\mathrm{a}}$ y Marzo 2 de 1751.

Rmº. P.e Nicolas Estrada

Luis Joseph Velázquez a Joaquín Saurin, Málaga, 23-II-1754.

AMM, CA, leg. 472, n. ${ }^{\circ} 26$ (es copia).

Muy Señor mio: no tenia yo noticia de los escritos de Juan Andrés Estrañ sobre las medallas; y para que yo le hubiese dado lugar en el ensayo, no bastaba que hubiese trabajado sobre nuestras medallas, sino era necesario, que determinadamente fuese de las Españolas desconocidas; pues solo de los trabajos, que acerca de ellas se han hecho, es de lo que allí trato. Yo aprecio mucho la noticia, que V. me da de este Escritor Español, cuya obra procuraré descubrir y acaso sabrá algo de ella D. Gregorio Mayans por haberse aplicado mas especialmente a la historia literaria de nuestra nacion.

Sobre el monumento de Cartagena escribí a Madrid, pero [sic=para] que en caso de ser cierta la especie, tomasen las providencias necesarias. V. me mandará pues sabe que soy suyo; y yo rogaré a Dios le gu.e m.s a.s.

Malaga, $23{\text { de } \mathrm{Feb}^{\circ} \text { de } 1754 .}^{2}$

B.L.M de V. su mayor serv.r

Luis Joseph Velazquez

Sr. D. Joachin Saurin 
Joaquín Saurin a Luis Joseph Velázquez, Murcia, 13-III-1755.

AMM, CA, leg. 472, n. 26 (es copia).

Murcia, 13 de Marzo de 1755

Muy Señor mio, y amigo de todas mi estimacion: en vista de la favorecida de $\mathrm{Vm}$. de $1^{\circ}$ del corriente quedo entendido de haber llegado a sus manos el Mapa del Obispado, y Reyno de Murcia, y asi mismo tener nuestro amigo Trabuco un exemplar del Origen de la Poesia castellana para remitirmelo, por lo que doy a Vm. las debidas gracias no dudando yo estará trabajada esta obra con el primor y delicadeza que se debe esperar del buen gusto, y exquisita erudicion de Vm. y ya tengo avisado el conducto por donde se me ha de enviar.

Remito a Vm. el adjunto Plan de todas las ciudades, villas y lugares que tiene este reyno de Murcia con Jurisdiccion ordinaria, en el qual se expresan sus respectivos vecindarios y tambien los Partidos a que pertenecen debiendo Vm. estar bien asegurado de la exactitud y puntualidad de dicho Plan, pues para su formacion me he valido unicamente de las noticias que he sacado de las Secretarias de Intendencia, y Ciudad, aunque este particular lo reservará Vm., y solo le servirá para que pueda formar seguro concepto de dichas noticias, las quales habiendomelas franqueado confidencialmente los Secretarios, no es justo se divulgue se han sacado de sus oficinas respecto a que no pueden dar ni aun copia simple del papel mas inutil de su encargo.

Asi mismo advierto a Vm. que aunque no se ponen en el referido Plan si no es los lugares que tienen Jurisdiccion ordinaria, esto no obsta para que se halle en el integramente el vecindario de todo el Reyno, pues en cada pueblo no solo se ponen los vecinos que tiene el casco de el sino es tambien los de las Aldeas o Villages de su Jurisdiccion como V.g.el vecindario de Murcia en el qual estan incluidos no solo los vecinos del recinto o casco de la Ciudad si no es tambien los de su huerta, y campo donde se hallan los lugares de Algezares, la Raya, Javalies, Aljucer, lugar de D. Juan, y otros muchos, pero estos se reputan todos como vecinos de Murcia y por tal se matriculan en sus Padrones por estar inmediatamente sugetos a la Jurisdiccion de Murcia, y no tener la propia dichos Lugares si solo Diputados, o alcaldes pedaneos que pone la Ciudad todos los años.

Los motivos porque no he puesto en el Plan estas Aldeas, o lugares que no tienen Jurisdiccion propia son lo primero por ser quasi moralmente imposible 
el averiguar su numero, y nombres, a causa de ser muchos, y algunos poco conocidos por su corta consideracion; lo segundo porque hallandose incluidos sus vecinos en los Pueblos que le sirven de Matrices y de cuya Jurisdiccion dependen no era posible el poner en cada uno de estos lugarcitos el vecindario que le corresponde desfalcandolo de la Partida pral. del Pueblo que tiene la Jurisdiccion, y a quien se le atribuye todo el num ${ }^{\circ}$ de vecinos, pues en las Secretarias de la Ciudad, Intendencia, y Guerra se hacen los alistamientos por Jurisdicciones del mismo modo que van en el Plan figurados, y finalmente poco me parece se puede aventurar en que se ignore el nombre de estos Lugares, siendo los mas de ellos de poquisima importancia.

Quedo trabajando sobre los demas particulares para satisfacer a Vm. lo menos mal que pueda, y deseando que Dios nro. Sr. g.e. a Vm. los m.s a.s que todos sus apasionados y servidores deseamos.

Sr. D. Luis Joseph Velazquez.

Luis Joseph Velázquez a Joaquín Saurin, Málaga, 9-VIII-1755.

AMM, CA leg. 472, n. 21 (es copia).

Amigo y S.r: en estos días me he aplicado a corregir, y poner corrientes las memorias para el viage de esse Reyno; y empezé por la formacion del Mapa, ajustandolo a los grados de latitud y longitud, y reduciendolo al Sistema de el Mapa universal de España, y sus Provincias en que ha dias que trabajo. De ello me han resultado las dificultades, que V. vera en la adjunta memoria, que remito a $\mathrm{V}$. para que preguntando a las personas que puedan dar razon de los territorios, examine la situacion de los pueblos, que en ella se mencionan; y por este medio pueda yo formar un Mapa completo de esse reyno, que hasta ahora no hay.

En la carta que incluyo, respondo al P. Ortega sobre todos los particulares que en la suya me tocaba: y al mismo tiempo le digo lo que pienso sobre las dos inscripciones que me prometia, que sin duda son las mismas que V. me hizo el favor de remitirme.

V. mandeme, pues sabe, que soy suyo; que yo cuidaré de rogar a Dios le guarde m.s a.s.

Malaga y Agosto 9 de 1755.

B.L.M. de V. 
Su mas $\operatorname{seg}^{\circ}$ serv. $^{\circ} \mathrm{r}$

Luis Joseph Velazquez.

Sr. D. Joachin de Saurin.

El P. Andrés Burriel a Joaquín Saurin, Toledo, 22-XII-1758.

AMM, CA, leg. 606.

Toledo, y Dr.e 22 de 1758

Sr. D. Joachin,

Mui $\mathrm{S}^{\circ}$ r mio. Respondo con alguna tardanza a la de Vmd. de 22 de Nov.e porque la recibi al salir de Madrid para esta Ciudad, donde he estado cercado de embarazos hasta ahora. Me ha sido de suma satisfaccion la honra, q.e Vmd. hace a mi obrilla y a mi porq.e sabiendo por el P. Quintanilla, y otros Jesuitas los talentos, juicio, y aplicación de Vmd., le era su especial aficionado, y deseaba merecer su buena gracia de alguna manera. Viva Vmd. mil a. por concedermela toda en pago de tan corto obsequio, como el del Informe. En el habra Vmd. visto ya, q.e no me olvide del particular afecto, debido a esa ciudad, en q.e estudie la theologia. Asi hice entrar en mi papel la mencion de su precioso Codigo del Fuero-Juzgo q.e copie años pasados, haviendolo hecho venir el Sr. Carvajal.

En las demas obras, q.e tengo proyectadas (y de q.e podra dar a Vmd. alguna noticia el P. Sanz Palanco, q.e llevó el Informe) tambien entraron otras Memorias de Murcia. Si a Vmd. fuere facil lograr copia entera de un Documento del Archivo de la Ciudad, de q.e solamt.e copio dn. Ascencio Morales una parte, dare las señas de el, según las tenian sus papeles.

Quando asi pido con tanta franqueza, quiero ser buen corresponsal en lo q.e alcanzan mis fuerzas sea en linea de letras, o en otra qualquiera. Sirva de testimonio este atrevimt $^{\mathrm{o}}$ de q.e desde luego me quiero constar por

El mas af ${ }^{\circ}$ serv. ${ }^{\circ}$ y Cap.n

de Vmd Q.S.M.B.

Andres Burriel

Anuncio a Vmd. todas las bendiciones del Sr. en las proximas festiv.s suyas.

Sr. Dn. Joachin Saurin, mui S.r mio. 
Lumiares a Joaquín Saurin, Alicante, 3-I-1780.

AMM, CA, leg. 617, Caja 30.

Mi Amigo: he visto el orig.l mans.t ${ }^{\mathrm{o}}$ de la Chronica de los Reyes Catolicos de Hernd. del Pulgar, escrita en 1518, anterior 24 años a la imp ${ }^{\text {a }}$ en $Z_{a r a g}{ }^{a}$ por

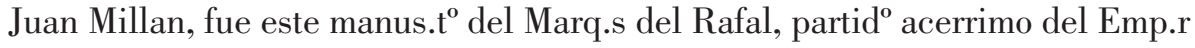
Carlos, en tpo. de la Guerra de Succe.sn como V. sabe, pero la chronica imp ${ }^{a}$ no esta con la exactitud corresp.te al orig.l he escrito a Sancha $p^{a}$ q.e la nueva ed.n se aga por el orig.l.

He llegado al $t^{\circ}$. pressiso $q$. nesesito de una copia de las Observac.s de V. sobre el theatro de Murviedro, q.e V. me franqueo, y yo copie, pero tubo la desgracia con otros lios de papeles, q.e se quemaron casualm.te. Sirvase V. faborecerme en mandarmela copiar q.e se lo agradecere sobre manera.

Digame V. si ha salido el tomito $4^{\circ}$ del Atlante Español, y hta. la vista mande a su Amigo

Lumiares

Alic.te $\mathrm{En}^{\circ} 3$ de 1780.

Sr. Dn. Joaquin Saorin.

Murcia.

Lumiares a Joaquín Saurin, Valencia, 5-v-1786.

AMM, CA, leg. 617, Caja 30.

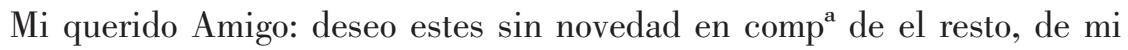
venerada familia.

El disparatado P.e Salmeron cita en su ultima disertacion Numismatica Laberintica, a la pag. ${ }^{a} 41$ una inscrip.n de Cieza, q.e pone en la $2^{\text {a }}$ disertacion en esta forma: Pag. ${ }^{\text {a }} 250$ n $^{\circ} 43$.

IMP. CAESAR. DIVI NERVAE

F. NERVAE TRAIANO AVG. 
GERMANICO DACICO

PONTIF. MAX. TRIB. POTEST.

COS. IIII. P.P. OPT. PRINCIP.

MVNICIPES CARTEIENSES

EIVS MAIESTAT. NVMINAE

DEVOTI L. BAE B.M. CLARO

CARTEIAENS. IL. VIR.

Dice q.e la copia de las memorias historicas q.e dejo en tomo en quarto M.S.S. el Lic.do Dn. Juan Robles [...]an, Autor de la Historia de la Santa Cruz de Caravaca, parece q.e no vio la obra de Salmeron pues escrive q.e se le comunico una copia de la Inscrip.n por mano segura: Corvalan fue Correspond. te epistolar de Higuera, siguió sus imposturas, y creo q.e esta inscrip.n esta añadida, a la q.e pone en la $\mathrm{Pag}^{\mathrm{a}}$. 244 en esta forma

\section{IMPERANTE CAESSARE \\ NERVA TRAIANO \\ AVGVSTO GERMANICO \\ TRIBVNITIAE POTEST. \\ COS.}

Como hizo Cascales con la de $\mathrm{St}^{\mathrm{a}}$ Victoria, siguiendo a Liutprando; o q.e tal inscrip.n fue forjada por Corvalan, pues ambas tienen visos de fingidas tanto en la ortog. $\mathrm{r}^{\mathrm{a}}$ como en los diftongos inusados el IMPERANTE estilo propio del arzobispo Dn. Ant ${ }^{\circ}$ de Guevara fraile fr.c $\mathrm{c}^{\mathrm{o}}$ igualmt.e uno de los romanos.

Quisiera merecerte me indagaras donde existe la obra de Corvalan, y sacarme una copia de las inscrip.s como el las trae, y una noticia de su obra esto es su methodo, y si el Salmeron se valio de las noticias y ilaciones de Corvalan esto es colocando dos Carteyas, aciendo a la [ilegible] de los olcades, Carteya, y transtornando los textos originales con la gallardia q.e el R.d ${ }^{\circ}$ Padre.

Sino tubieres la proporcion de ver las memorias historicas M.S.S. en la de la Cruz de Caravaca puede ser halles algo q.e me aproveche, igualmt.e te estimare todo quanto contribuya contra las disertaciones, y resumen historial del $\mathrm{Rd}$. Salmeron.

En el Cap. X. pag. 46 de la disertacion Numismatica escrive cierto erudito Amigo mio me envio a decir con familiar satisfac. $n$ aunq.e con aseveracion seria q.e dha. ciudad, no tubo su sitio en el monte vecino a Cieza como yo decia q.e alli estubo según Ptolomeo Seguisa ... estrañe esta desición tan absoluta etc. y recelo 
seas tu el erudito dime si es assi $\mathrm{p}^{\mathrm{a}}$ q.e le cargue la mano sobre ese punto sin nombrarte pues el no te nombra.

En Madrid se esta imprimiendo mi Carta a los Mohedanos contra su historia literaria, aquí la Dianium, y las inscrip.s de Cartago Nova, y en poniendola en limpio las Cartas al P.e Salmeron bajo el nombre de el Bachiller Sanson Carrasco q.e te re[mitire] por Orihuela en la prim ${ }^{\mathrm{a}}$ ocasión.

El Thesoro de Ynscrip.s del R.n ${ }^{\circ}$ de Valencia estan quasi en limpio, y tengo ya 12 laminas sacadas, sera la colección mas completa q.e abra por su exactitud.

Tu conservate bueno, y no olvides a un verdadero Amigo q.e te ama como q. es

Lumiares

P.D. No digas nada sobre la Carta contra Salmeron por haora.

Valencia Mayo 5 de 1786.

Mi g.r Amigo Dn. Joaq.n Saurin. 